\title{
Regulatory Update: CARB Passes USA's First Regulations for Heavy-Duty Diesel Engine Replacement Filters
}

\author{
Mansour Masoudi ${ }^{1}$ \\ Received: 26 April 2016/Accepted: 3 May 2016/Published online: 13 May 2016 \\ (C) Springer International Publishing Switzerland 2016
}

Emission regulations play a significant role in assuring that manufacturers of internal combustion engines utilize emission control devices. For on-road, heavy-duty Diesel vehicles, any replacement of such emission devices during the initial warranty period (5 years, 100,000 miles, or 3000 hours of operation in California, whichever comes first) is covered by the manufacturer, while any replacement thereafter is the vehicle owner's responsibility.

Vehicle owners who, past the initial warranty period, opt to replace such devices using the OEM-approved parts have come to the realization that this is a costly option, hence demanding lower-cost replacement devices commonly known as "aftermarket" parts. Not so fast, says the California Air Resources Board (CARB), as, historically speaking, aftermarket parts, especially when produced by non-OEM manufacturers, are not required to meet the same benchmark as the OEM-produced parts do.

This is where the market and the regulations meet once again: Since automotive pollution is of major public interest and is clearly regulated, one can simply understand why regulatory agencies, such as the CARB, would be inclined to devise rules and guidelines for replacing components of emission control systems.

On Friday 22 April 2016, the CARB officially adopted its drafted rules and guidelines for replacement parts for Diesel Particulate Filters (DPF), the first of its kind for Diesel exhaust emission control components in the USA. For now, the CARB rules are limited to 2007 through 2009 model year heavy-duty

Mansour Masoudi

mansour.masoudi@emissol.com

1 Mill Creek, WA, USA
Diesel engines for on-road platforms; these were the vehicles having lower engine-out NOx and without urea SCR systems.

With such CARB regulations for replacement DPF parts now becoming hard-wired into the California Code of Regulations, one wonders how such rules will gradually impact other landscapes of replacement DPF technologies and markets outside of California. One potential impact may be on the other 49 US states, a jurisdiction of interest to the US EPA. Another may be that its various versions could be adopted or worked into existing regulations in other countries or regions, such as within the EU member countriesor regions, such as within the EU member countries.

California replacement DPF rule-making did not come as a surprise. The need for a structured approach for lower-cost replacement DPFs had been felt for some time. On the one hand, lower-cost replacement DPFs were needed to provide relative financial ease for vehicle owners; on the other, such DPFs had to meet emission reduction performance benchmarks satisfactory to the public at large. Indeed, lack of such regulations had created a singularity between California and the rest of the country. In California, vehicle owners were so far left with only one choice: the higher-cost OEM-approved replacement DPFs; outside of California, the picture has not been as crisp: There existed (and continues to exist) replacement DPFs over a large spectrum of the good, the bad, and the ugly. While some non-OEM replacement DPF producers appear to yield replacement parts having suitable qualities, it is however not hard to notice other replacement DPFs available in the market barely meeting minimally acceptable performance benchmarks.

It is hence fair to predict the recent rule-making in California, indeed the first of its kind, will come without neither its challenges nor its widespread impact; most notably, (a) there will be an initial period where these newly adopted technology, quality and rules will help greatly fine-tune the replacement DPF markets, while such markets will help fine- 
tune the rules in return; (b) CARB regulations may gradually start showing its impact on replacement DPF products available in the 49 states; and (c) the good, the bad, and the ugly will soon take note that the days on compromising on replacement DPF quality are starting to be counted. (Obviously, "the good" have not much to worry about.)
Looking forward, one can only applaud the CARB for taking this significant lead in streamlining the aftermarket DPF quality and marketplace within California. Its impact will likely shape the quality of replacement DPFs well outside of California; that may just be a matter of time. 